\title{
The dynamics of productivity in Swiss universities
}

\author{
Thomas Bolli ${ }^{1}$ Mehdi Farsi ${ }^{2}$
}

Published online: 4 June 2015

(c) Springer Science+Business Media New York 2015

\begin{abstract}
This paper analyzes the productivity of Swiss university departments between 1995 and 2012. Using a parametric input distance function we estimate and decompose the Malmquist productivity indexes in line with Fuentes et al. (J Product Anal 15:79-94, 2001) and Atkinson (J Bus Econ Stat 21:284-294, 2003). The adopted model is a mixed-effects model with department-specific fixed effects and random time trends. An autoregressive stochastic term is used to model inefficiency shocks with gradual dissipation by adaptation and learning. The results indicate a negative trend in Malmquist index starting from 2002 , with an average rate of about $1 \%$ per year. However, our analysis of scale effects indicates that this decline is more or less offset by universities' constant expansion and the resulting economies of scale. The results point to various patterns of overall productivity change across scientific fields that are closely related to potential productivity gains due to scale economies. In contrast to some previous studies we do not find any significant relation between productivity development and the Bologna reform.
\end{abstract}

Keywords Parametric distance function - Malmquist index $\cdot$ Decomposition $\cdot$ Swiss universities $\cdot$ Bologna accords

Thomas Bolli

bolli@kof.ethz.ch

Mehdi Farsi

mehdi.farsi@unine.ch

1 ETH Zurich, KOF Swiss Economic Institute, Leonhardstrasse 21, 8092 Zurich, Switzerland

2 Faculty of Economics, University of Neuchâtel, A.L. Breguet 2, 2000 Neuchâtel, Switzerland
JEL $\quad$ C23 $\cdot$ D24 $\cdot$ I $23 \cdot \mathbf{J} 24$

\section{Introduction}

Swiss universities with more than $70 \%$ public funding (SFSO 2010b) are among the world's most expensive universities for tax payers. The rapid growth in public expenditures and federal funds reflects the government's priority in promoting world-class universities. An analysis of productivity growth can be used to assess to what extent additional funds have resulted in a better performance. The dynamics of productivity is particularly interesting in the last two decades when the Swiss universities have undergone a number of reforms similar to those initiated in many other European countries.

In a country with a strongly heterogeneous higher education system, government authorities have aimed at improving accountability and transparency by uniform and compatible standards. A notable reform starting from 1995 was the aggregation of various applied tertiary schools to seven regional "universities of applied sciences" (Confederation 1995), which was expected to lighten the financial burden of higher education with less expensive alternatives. The most important reform implemented over an extended period of time has been brought about by the Bologna Accords in 1999. As an early signatory, Switzerland has followed Bologna guidelines that are closely reflected in the instructions issued by the "Rectors' Conference of the Swiss Universities" in 2003 (CRUS 2003). Accordingly, the Swiss universities increased their coordinated efforts to transform their traditional singledegree system (Licentiate) to a system offering Bachelor and Master programs. Year 2003 can be marked as a culminating point by two other initiatives, namely the 
introduction of quality assurance guidelines (SUC 2003) and the adoption of intellectual property policy by the country's two engineering schools (ETH Zurich and Lausanne) in order to control and eventually capitalize on their research output (ETH 2004).

The Bologna reforms are often considered as measures that could improve the performance of European universities (see, e.g., Borghans and Cörvers 2009). It is argued that by enhancing mobility of students and competition among universities, compatibility will result in improved performance. ${ }^{1}$ In practice, however, the excessively slow pace of implementation and the observed difficulties in the usage of unified systems have raised questions about the desirability of any top-down reform (Kruecken 2007; Neave and Amaral 2008; Crosier et al. 2007).

Switzerland presents itself as an interesting case in which, after a decade of transition between the old system and the unified model, the Bologna's harmonization process has reached its final stage. This period coincides with a more or less stable growth of about $3 \%$ per year in the country's public expenditures on universities (SFSO 2010b). Unlike certain European countries that have reportedly shown little success in the implementation of the Bologna system (Veiga and Amaral 2009; Witte 2008), Switzerland can claim an overall success in achieving convergence in its higher education system.

An analysis of productivity in Swiss universities could be used as an empirical basis for guiding higher education policies in Switzerland but also in other countries committed to Bologna reforms. The topic has received attention in two recent studies (Olivares and Schenker-Wicki 2012; Agasisti and Bolli 2013), but the results show some conflicting trends warranting further research. While the former study points to important gains due to scale effects combined with a negative technological progress, the latter suggests a general decline in productivity but with little evidence of positive scale effects. As an extension to these studies in both data and methodology, this paper is another attempt in analyzing the productivity growth in Swiss universities with a sample period covering the implementation of harmonization reforms. In particular, we use a panel data set from twelve universities over a 13-year period from 1995 to 2012 . The data are available by six scientific fields differentiated into fifteen subgroups, allowing for a department-level analysis with about 1700 observations from about a hundred university departments. We use a translog input distance function with five inputs including labor inputs in four categories, a single capital input measured by nonlabor expenditures and three outputs, namely enrolled students and research grants in two

\footnotetext{
${ }^{1}$ Mobility and competition are among the key policy points recommended by many experts such as Aghion et al. (2008).
}

categories. We focus on the Malmquist index which measures productivity growth without accounting for scale effects. The adopted methodology is in line with Fuentes et al. (2001) and Atkinson et al. (2003), allowing a parametric distance function with no a priori assumption regarding returns to scale. The scale effects are estimated in line with the approach proposed by Orea (2002). The econometric specification incorporates individual intercepts estimated via fixed effects to account for different sources of heterogeneity, random time trends and an autoregressive stochastic term representing the variation of technical efficiency. The mixed-effects specification allows a separation of temporal effects from the time-invariant heterogeneity, while allowing an individual differentiation in the estimates of productivity growth.

The results suggest a gradual decline of about $1 \%$ per year in the Malmquist productivity index after a period of stagnation until around 2002. The decomposition analysis suggests that most of the decline can be associated with a negative technological progress rather than efficiency issues. However, the estimated scale effects show a constantly rising productivity due to the economies of scale, which offsets the productivity decline measured by Malmquist index. These opposing trends result in an overall stagnation rather than persistent growth in total factor productivity.

The remainder of the paper is organized as follows. The next section relates this paper to the existing literature concerning the measurement of university productivity over time. Sections 3 and 4 provide descriptions of the econometric specification and the data, respectively. Section 5 discusses our main results. Section 6 attempts to relate productivity growth to international openness and the progress of the Bologna reform. Section 7 concludes the paper.

\section{Review of the literature}

Empirical research in university productivity and efficiency is documented in a relatively small but rapidly growing body of literature. Some of these studies are reviewed in two surveys by Worthington (2001) and Johnes (2004). As far as productivity growth is concerned, this literature is characterized by two distinct methodologies: nonparametric estimation of Malmquist index (Malmquist 1953) derived from a data envelopment analysis (DEA) in line with Färe et al. (1994) and parametric estimation of translog functions using stochastic frontier analysis (SFA) as in Nishimizu and Page (1982). ${ }^{2}$

\footnotetext{
${ }^{2}$ For more recent applications see Saal et al. (2007) and Das and Kumbhakar (2012).
} 
Fuentes et al. (2001) provide a discussion of theoretical differences between the two methods. However, few studies have compared the empirical outcomes of the two approaches in the case of university productivity. An exception is Kempkes and Pohl (2010) who report more or less similar results for German universities' data for the 1998 to 2003 period.

A thorough comparison of these methods is beyond the scope of this study. It is nevertheless important to note that both methods have appealing advantages: As pointed out by Fuentes et al. (2001), the indivisible production factors are readily amenable to discrete ratios such as the Malmquist index. On the other hand, parametric methods are easily adaptable to panel data providing a possibility to account for time-invariant heterogeneity.

The advantages of parametric methods can be combined with the intuitiveness of the Malmquist productivity index. In particular, the parametric methods proposed by Fuentes et al. (2001) and Atkinson et al. (2003) allows us to exploit the panel aspects of the data while retaining the discrete nature of the productivity measure in consistence with economic data. Adopting a parametric approach to estimate the Malmquist productivity index, this paper is the first of the kind in the context of higher education.

In the case of Switzerland, the related empirical literature is limited to three studies: Agasisti and Bolli (2013) examine the productivity impact of the Bologna reform using an output distance function estimated at the department-level from 1995 to 2010, whereas Olivares and Schenker-Wicki (2012) estimate the development of universities' technical efficiency between 1999 and 2007, using a Malmquist index based on DEA. Finally, Filippini and Lepori (2007) estimate a variable cost function using a true random effects SFA (Greene 2005), on the data between 1994 and 2003. Olivares and Schenker-Wicki (2012) report a generally positive development in technical efficiency, significant productivity gains due to scale effects, but negative technological change. The latter finding is consistent with a positive trend in costs reported by Filippini and Lepori (2007). Agasisti and Bolli (2013)'s results indicate a general productivity decline but a positive productivity impact for Bologna reforms. While the authors do not examine the scale effects, their regression results indicate decreasing returns to scale suggesting that the expansion of universities could have detrimental productivity effects. This is in direct contrast to Olivares and Schenker-Wicki (2012) but also to other studies. Namely, Filippini and Lepori (2007) report significant economies of capacity utilization, suggesting that output expansion can increase productivity. Similarly, Olivares and Wetzel (2011)'s analysis using an output distance function favors the presence of economies of scale in German universities.
Among the empirical studies of university productivity in other countries we focus on those that have used relatively long panel data. Both DEA and SFA approach have been used. Flegg et al. (2004) and Flegg and Allen (2007) have adopted the DEA approach for British universities. Their findings suggest productivity growth due to a shift in the production frontier over periods of 1980-1992 and 1994-2003, respectively. Similarly, Johnes (2008) reports a moderate productivity growth in English universities between 1996 and 2004, partly offset by a decrease in the average level of efficiency. On the other hand, Stevens (2005) applies the SFA approach to English and Welsh universities between 1995 and 1997. He finds evidence for a technological regress but an increase in technical efficiency. Robst (2001) finds a positive trend coefficient in his cost function estimates for US universities between 1991 and 1995. Kuo and Ho (2007) analyze the efficiency of Taiwanese universities in the period 1992-1999. They find evidence for technological progress as well as improvements in the technical efficiency.

In the case of Australian universities Abbott and Doucouliagos (2009) apply Battese and Coelli (1995)'s SFA model to data from 1995 to 2002 . They find that while the production frontier has shifted outward, the efficiency level of universities has decreased. Worthington and Lee (2008) have used DEA and reported productivity growth between 1998 and 2003. They identified technological progress as a main source of productivity. On the other hand, using a parametric stochastic frontier in line with Cornwell et al. (1990), Horne and $\mathrm{Hu}$ (2008) analyze data between 1995 and 2002 and find no discernible time trend.

Before turning to this paper's contribution it is worth noting that productivity measures are necessarily based on immediate outputs rather than long-term impacts. To the extent that a university output is an investment in human capital to be assessed in the long run, these productivity measures are all but incomplete pictures of academic performance. This shortcoming can be partly countered by using quality proxies such as publication quality, citations and graduates' employment prospect. However, most of these measures could vary strongly among different fields. Moreover, most of the differences regarding the mix of various fields of education and research across universities are omitted from empirical models. Therefore, productivity estimates might be biased due to structural differences that remain unobserved due to data limitations or measurement difficulties. Virtually all previous studies have pooled the longitudinal data across universities and hence do not exploit the panel data advantages to account for unobserved heterogeneity. Among the exceptions we should mention Filippini and Lepori (2007), Horne and $\mathrm{Hu}$ (2008) and Agasisti and Bolli (2013) that include university or department-specific effects in their estimations. 
The adopted approach in this paper is similar to Horne and $\mathrm{Hu}$ (2008) and Farsi (2008) in that we use individual intercepts to account for the unobserved factors pertaining to an individual production unit (here, a university department). Recognizing the difficulty of measuring quality, we assume that unobserved differences across universities can be captured by time-invariant factors specific to each university department. This assumption implies that the unaccounted temporal variations can be associated with productivity changes. It is important to note that a department-level analysis reduces potential biases due to different mixes of fields in a university, but also alleviates the apparent developments due to specific changes in scientific fields.

\section{Methodology}

We use an input distance function to model the productivity changes measured by a Malmquist index. The adopted methodology is similar to the approaches proposed by Atkinson et al. (2003) and Fuentes et al. (2001). The input distance function at any period, $t$, is defined as the maximum possible reduction in input vector, $x$, while retaining a given level of output vector, $y$, and time-invariant characteristics, $z$ :

$D_{I}\left(x_{j t}, y_{j t}, z_{j}, t\right)=\max \left\{\varrho:\left(x_{j t} / \varrho\right) \in L\left(y_{j t}, z_{j}, t\right)\right\}$

where subscript $j$ denotes the production unit (here, a university department). $L\left(y_{j t}, z_{j}, t\right)$ is the feasible input set and $\varrho$ is a scalar $(\varrho \geq 1)$ measuring possible reductions in inputs, whose minimum value $(\varrho=1)$ corresponds to fully efficient production units. A measure of relative inefficiency can be defined as $D_{I}$, representing the relative excess in input factors due to technical inefficiency. The input distance function needs to satisfy certain regularity conditions. Namely, it must be decreasing in outputs and nondecreasing and linearly homogeneous in inputs.

Assuming separability between observed input/output variables $\left(x_{j t}, y_{j t}\right)$ and the excluded characteristics and time $\left(z_{j}, t\right)$, the distance function in logarithm can be written in a translog functional form as in Coelli and Perelman (2000):

$\ln D_{I}\left(x_{j t}, y_{j t}, z_{j}, t\right)=\operatorname{TL}\left(x_{j t}, y_{j t}\right)+\theta\left(z_{j}, t\right)$

where $\operatorname{TL}\left(x_{j t}, y_{j t}\right)$ is a translog function of observables and $\theta\left(z_{j}, t\right)$ is an unknown function that includes the model's incidental parameters. We specify the stochastic function $\theta\left(z_{j}, t\right)$ as a function of department-specific characteristics $z_{j}$, plus a quadratic function of time:

$\theta\left(z_{j}, t\right)=f\left(z_{j}\right)+\phi_{j}^{1} * t+\phi_{j}^{2} * t^{2}$

where $f($.$) is an arbitrary function and the coefficients \phi_{j}^{1}$ and $\phi_{j}^{2}$ correspond to the linear and quadratic trends representing the temporal variation of the distance function for department $j .^{3}$

The department $j$ 's technical inefficiency measured by the distance function $\left(\ln D_{I}\right)$ can be decomposed into a time-invariant part $u_{j}$, and a time-varying part $\epsilon_{j, t}$ :

$\ln D_{I}\left(x_{j t}, y_{j t}, z_{j}, t\right)=u_{j}+\epsilon_{j, t}$

where $u_{j}$ is a department-specific effect and $\epsilon_{j, t}$ is an autoregressive process defined below.

The linear homogeneity in inputs requires that any proportional increase in all inputs causes the same increase in the distance function. Imposing this condition to Eq. 1 yields

$$
\begin{aligned}
-\ln x_{1 j t}= & \ln D_{I}\left(x_{j t}^{*}, y_{j t}, z_{j}, t\right) \\
& -\ln D_{I}\left(x_{j t}, y_{j t}, z_{j}, t\right)
\end{aligned}
$$

where $x^{*}=x / x_{1}$ is the ratio of inputs to an arbitrary input $x_{1}$ used for normalization. Thanks to linear homogeneity it does not matter which input is selected as the numeraire. Substituting $\ln D_{I}\left(x_{j t}^{*}, y_{j t}, z_{j}, t\right)$ using Eqs. 2 and 3 and $\ln D_{I}\left(x_{j t}, y_{j t}, z_{j}, t\right)$ to the right-hand side of Eq. 4 yields

$$
\begin{aligned}
-\ln x_{1 j t}= & \operatorname{TL}\left(x_{j t}^{*}, y_{j t}\right)+f\left(z_{j}\right) \\
& +\phi_{j}^{1} * t+\phi_{j}^{2} * t^{2}-u_{j}-\epsilon_{j, t}
\end{aligned}
$$

The translog parameters must satisfy the usual symmetry restrictions. ${ }^{4}$ The linear homogeneity condition in a translog function can be readily expressed by linear constraints on the coefficients. Namely, in our case: $\sum_{r=1}^{5} \beta_{r}=1$, $\sum_{s=1}^{5} \beta_{r s}=0, \forall r$ and $\sum_{r=1}^{5} \zeta_{r m}=0, \forall m$. Hence, expanding the translog function for three outputs and five inputs, we have:

$$
\begin{aligned}
\mathrm{TL}\left(x_{j t}^{*}, y_{j t}\right)= & \sum_{r=2}^{5} \beta_{r} \ln x_{r j t}^{*}+\frac{1}{2} \sum_{r=2}^{5} \sum_{s=2}^{5} \beta_{r s} \ln x_{r j t}^{*} * \ln x_{s j t}^{*} \\
& +\sum_{m=1}^{3} \gamma_{m} \ln y_{m j t}+\frac{1}{2} \sum_{m=1}^{3} \sum_{n=1}^{3} \gamma_{m n} \ln y_{m j t} * \ln y_{n j t} \\
& +\sum_{r=2}^{5} \sum_{m=1}^{3} \zeta_{r m} \ln x_{r j t}^{*} * \ln y_{m j t}
\end{aligned}
$$

By substituting the translog function from Eq. 7 into Eq. 6 we can obtain an empirically estimable distance function:

\footnotetext{
${ }^{3}$ In addition to the quadratic form, we have considered several alternatives, including cubic time trends, year dummies and another specification with piecewise linear trends in 2- to 4-year intervals. Our preliminary analyses indicated that the results are not sensitive to the specification of the time trends. Similar to Cornwell et al. (1990), Lee and Schmidt (1993), Kneip et al. (2003) and Sickles (2005), we favor a quadratic trend because it allows one to keep the number of trend coefficients within a reasonable limit.

${ }^{4} \beta_{r s}=\beta_{s r}, \gamma_{m n}=\gamma_{n m}$ and $\zeta_{r m}=\zeta_{m r} \forall r, s, m, n$
} 


$$
\begin{aligned}
-\ln x_{1 j t}= & \sum_{r=2}^{5} \beta_{r} \ln x_{r j t}^{*}+\frac{1}{2} \sum_{r=2}^{5} \sum_{s=2}^{5} \beta_{r s} \ln x_{r j t}^{*} * \ln x_{s j t}^{*} \\
& +\sum_{m=1}^{3} \gamma_{m} \ln y_{m j t}+\frac{1}{2} \sum_{m=1}^{3} \sum_{n=1}^{3} \gamma_{m n} \ln y_{m j t} * \ln y_{n j t} \\
& +\sum_{r=2}^{5} \sum_{m=1}^{3} \zeta_{r m} \ln x_{r j t}^{*} * \ln y_{m j t} \\
& +\alpha_{j}+\phi_{j}^{1} * t+\phi_{j}^{2} * t^{2}-\epsilon_{j t}
\end{aligned}
$$

with $\alpha_{j}=f\left(z_{j}\right)-u_{j}$ denoting the individual intercepts. Note that the estimation of the distance function is equivalent to a regression model (Eq. 8) in which the numeraire input variable, $x_{1}$, with a negative sign is regressed on all other observables including the remaining input variables normalized by the numeraire input, that is, $x_{r}^{*}=x_{r} / x_{1}$ (see, e.g., Coelli et al. 2005). In principle, the model in Eq. 8 may include any observed output characteristics in addition to the included inputs and outputs. ${ }^{5}$

Note that because the distance function $\left(D_{I}\right)$ is greater or equal to one, its $\log \left(\ln D_{I}\right)$ is nonnegative. This puts a sign restriction on the composed stochastic term in Eq. 4, hence a lower bound on the time-invariant component of the distance function $u_{j}$. However, as shown in Eq. 8, the term $u_{j}$ is captured by department-specific intercepts that are canceled out in the calculation of efficiency changes. ${ }^{6}$ In other words, while the department-specific intercepts $\alpha_{j}$ are identified in the regression Eq. 8, the terms $f\left(z_{j}\right)$ and $u_{j}$ cannot be identified separately. Equation 8 is a mixed-effects linear model with individual fixed effects $\alpha_{j}$, and random trend coefficients $\phi_{j}^{1}$ and $\phi_{j}^{2}$. Noting that the random coefficients are defined on time trends, the individual intercepts and random coefficients are identified separately. The model can be solved using appropriate distribution assumption for the error term $\epsilon_{j t}$. ${ }^{7}$ Concretely, we assume that these department-specific trends have a bivariate normal distribution, that is: $\left(\phi_{j}^{1}, \phi_{j}^{2}\right) \sim N\left(\lambda^{p}, \Sigma_{\phi}\right) .\left(\lambda^{1}, \lambda^{2}\right)$ represent the average time trends. ${ }^{8} \Sigma_{\phi}$ is a homoscedastic variance-covariance matrix. ${ }^{9}$

\footnotetext{
5 In an alternative specification discussed in Sect. 6, we have considered additional variables such as the share of international students and the implementation of the Bologna reform.

${ }^{6}$ See also Eqs. 9, 11 and 12.

${ }^{7}$ We estimate Eq. 8 using the expectation-maximization (EM) algorithm programmed by the xtmixed command in Stata 12 .

${ }^{8}$ We also tested a version where we assume that these departmentspecific trends vary around field-specific mean values with a bivariate normal distribution, that is: $\left(\phi_{j}^{1}, \phi_{j}^{2}\right) \sim N\left(\lambda_{f}^{p}, \Sigma_{\phi}\right)$. Subscript $f$ denotes the scientific field and the means of this distribution $\left(\lambda_{f}^{1}, \lambda_{f}^{2}\right)$ represent the average time trends for each scientific field.

9 We assumed no correlation, because our preliminary regressions indicated that the correlation coefficients were mostly insignificant.
}

In our specification, the stochastic term, $\epsilon_{j t}$, is defined as an autoregressive process of order one, i.e., $\epsilon_{j t}=\rho \epsilon_{j t-1}+$ $v_{j t}$, where $v_{j t}$ is an iid normal error with variance $\sigma_{v}^{2} . \rho$ is the autocorrelation coefficient that satisfies $0<\rho<1$. With the autoregressive process, we assume that each period brings about an improvement in the persistent inefficiency from previous years reflected in $\rho$, but also has its own new shock $v_{j t}$. The value of $\rho$ can indicate the rate of learning and the persistency of inefficiency. Roughly speaking, according to the autoregressive model with $\rho<0$, the remaining effect of an inefficiency shock after $n$ years will decrease to $\rho^{n}$ of the initially induced inefficiency.

The random coefficients of time trends $\left(\phi_{j}^{1}, \phi_{j}^{2}\right)$ allows a differentiation in productivity changes across departments. It is important to note that the potential flexibility brought about by these random coefficients might vary in different contexts. An adequate assessment of the possible advantages requires several applications to various setups, which is beyond the scope of this paper. However, as far as the present application is concerned the adopted model allows us to identify the rate of technological progress in each one of the six scientific fields, while accounting for variations across departments with fixed effects. We contend that this is an important flexibility of the model because many potential drivers of productivity such as globalization could vary across scientific fields (see, e.g., Borghans and Cörvers 2009). Assuming that competition fosters productivity growth, one could expect a higher productivity growth in disciplines such as science and engineering that are more exposed to globalization compared to certain fields such as law that have strong country specificity.

Productivity could also vary across scientific disciplines because of different developments of complexity and asymmetry of information. In order to ensure efficiency, organizations and incentive mechanisms need to adapt. For instance higher complexity might require a higher wage differential due to efficiency wages. To the extent that the adjustment of incentive mechanisms is difficult in public organizations, one can expect a lower productivity growth in disciplines that have gone through substantial progress, hence greater complexity. A plausible example is the relatively rapid transformation of business and economics into highly quantitative disciplines during the last decades, causing difficulties and disagreements in evaluating academic activities. Assuming that institutions do not allow a rapid adjustment to such developments (for instance by adjusting wages), we might expect a lower productivity growth in these fields compared to other disciplines.

\subsection{Malmquist index and its decomposition}

Based on the distance function estimations, we predict the corresponding Malmquist indices (Caves et al. 1982a, b). 
In the case of input distance functions, for any given production unit $j$, at a given period $t$, the Malmquist productivity index measures the decrease in the distance function between two periods $t$ and $t+1$, while fixing the technology frontier either at period $t$ or at $t+1$. In line with Fuentes et al. (2001), we define the Malmquist index as the predicted value of the input distance function in period $t$, divided by the predicted value of the function in period, $t+1$, while retaining the frontier at $t$. Therefore, using Eq. 5 we can write the Malmquist index as:

$$
\begin{aligned}
M\left(x_{j t}, y_{j t}, x_{j, t+1}, y_{j, t+1}, z_{j}, t\right)= & \frac{D_{I}\left(x_{j t}, y_{j t}, z_{j}, t\right)}{D_{I}\left(x_{j, t+1}, y_{j, t+1}, z_{j}, t\right)} \\
= & \exp \left[\operatorname{TL}\left(x_{j t}, y_{j t}\right)\right. \\
& \left.-\operatorname{TL}\left(x_{j, t+1}, y_{j, t+1}\right)\right]
\end{aligned}
$$

Since $D_{I}$ is unobserved, we calculate the translog function $T L$.) based on Eq. 7 and the parameter estimates of Eq. 8. Note that the estimated trend coefficients do not enter the expression of the Malmquist index, thus allowing for technical progress to be included in productivity growth.

Färe et al. (1997) suggest to write the Malmquist index as the product of two components. The first term, technical efficiency change (TE), captures the change in the distance to the current frontier. The second element, called technical change $(T)$, uses the inputs/outputs of period $t+1$, but allows the production technology (frontier) to shift. The Malmquist index can therefore be decomposed into two components, respectively, representing changes in technical efficiency and technical progress:

$$
\begin{aligned}
M\left(x_{j t}, y_{j t}, x_{j, t+1}, y_{j, t+1}, z_{j}, t\right) & \\
= & \mathrm{TE}\left(x_{j t}, y_{j t}, x_{j, t+1}, y_{j, t+1}, z_{j}, t, t+1\right) \\
& * T\left(x_{j, t+1}, y_{j, t+1}, z_{j}, t, t+1\right) \\
= & {\left[\frac{D_{I}\left(x_{j t}, y_{j t}, z_{j}, t\right)}{D_{I}\left(x_{j, t+1}, y_{j, t+1}, z_{j}, t+1\right)}\right] } \\
& *\left[\frac{D_{I}\left(x_{j, t+1}, y_{j, t+1}, z_{j}, t+1\right)}{D_{I}\left(x_{j, t+1}, y_{j, t+1}, z_{j}, t\right)}\right]
\end{aligned}
$$

where the two components can be written as:

$$
\begin{aligned}
& \operatorname{TE}\left(x_{j t}, y_{j t}, x_{j, t+1}, y_{j, t+1}, z_{j}, t, t+1\right) \\
& \quad=\exp \left[\operatorname{TL}\left(x_{j t}, y_{j t}\right)-\operatorname{TL}\left(x_{j, t+1}, y_{j, t+1}\right) .\right. \\
& \left.\quad-\phi_{j}^{1}-\phi_{j}^{2}(1+2 t)\right] \\
& T\left(x_{j, t+1}, y_{j, t+1}, z_{j}, t, t+1\right) \\
& \quad=\exp \left[\phi_{j}^{1}+\phi_{j}^{2}(1+2 t)\right]
\end{aligned}
$$

\subsection{Scale effects}

The Malmquist productivity index abstracts from scale effects. This limitation has prompted certain researchers to propose extensions of the Malmquist index. Orea (2002) is a prominent example that is applicable to parametric distance functions. Adapting his method to the case of input distance functions, we can write the productivity gains due to scale effects based on marginal effects in period $t$ as:

$$
\begin{aligned}
\mathrm{SE}= & \exp \left[\left(1+\frac{1}{\sum_{m=1}^{3} \partial \ln D_{I} / \partial \ln y_{m}}\right)\right. \\
& \left.* \sum_{m=1}^{3}\left\{\partial \ln D_{I} / \partial \ln y_{m} * \ln \left(\frac{y_{m}^{t+1}}{y_{m}^{t}}\right)\right\}\right]
\end{aligned}
$$

Note that all partial derivatives with respect to output should have a negative sign in the input distance function given by Eq. 8. Adjusting the Malmquist productivity index for the scale effects yields an overall TFP index that includes Malmquist productivity as well as productivity gains that are purely due to scale effects:

$\mathrm{TFP}=M * \mathrm{SE}$

In the context of higher education, technical change can be specified as technological improvements in equipment as well as managerial and organizational innovations. Typical examples include new technologies in research laboratories, computation centers and administration systems, but also curriculum reforms and initiatives for better coordination between various activities. In principle, technical change should manifest as positive productivity growth, hence technical progress. However, the frontier could experience an inward shift when the production is burdened by external constraints. Changes in technical efficiency can be related to learning and adaptation to new challenges due to various developments that might require new qualifications and organizational arrangements. New challenges can be considered as inefficiency shocks that appear at each period and gradually dissipate by learning and adaptation. The productivity gains due to scale effects are due to output expansion, that is, the growth of student body as well as research demand faced by universities. Such scale effects are tantamount to an outward frontier shift.

\section{Data and specification}

Ideally, the universities' ultimate outputs should be measured by the long-term added value of their research and education on the society's human capital. Lacking adequate outcome measures, empirical studies generally use simple measures of intermediate outputs such as number of graduates, enrollments, publications and financial grants (see, e.g., Abbott and Doucouliagos 2009; Agasisti and Johnes 2010). Main input factors are generally labor inputs including teaching and research staff and in some cases 
capital inputs (for instance, Filippini and Lepori 2007; Eckles 2010).

The model adopted in this paper includes three outputs and five inputs. The input factors include four labor inputs extracted from the personnel data, namely the number of full-time equivalent employees in four categories: "Professors," "Lecturers," "Assistants" and "Administrative and technical staff." 10 The fifth input is the department's nonlabor expenditure, i.e., all expenditures except for wages and social security payments. Adopting a residual approach, we assume that the university's nonlabor costs can be used as a proxy for capital inputs. Measuring capital inputs by their costs ignores the variation of capital price across university departments. Moreover, in our data, the nonlabor costs do not include the costs of many university buildings owned by the Swiss cantons. However, as the related differences across university departments are likely to be constant over time, we expect that these differences can be reasonably captured by individual fixed effects. ${ }^{11}$

The three outputs included in the model are total enrollments, research grants from the Swiss National Science Foundation (SNSF) and other external funds. In line with Johnes and Johnes (2008) and Thanassoulis et al. (2009) the number of enrolled students at the university captures the teaching output. The student body can be grouped into four categories corresponding to the degree programs offered in the sample period, that is, $\mathrm{PhD}$, Licentiate, Bachelor and Master. In our sample, the two latter programs appear starting from 2002, whereas Licentiate is the single undergraduate degree program prior to the Bologna reform. We exclude PhD students because they are generally employed by the university as part-time assistants, thus included as a labor input. In order to have a clear definition we aggregate all students into one group, including Licentiate, Bachelor and Master students.

Similar to previous studies (Abbott and Doucouliagos 2009; Agasisti and Johnes 2010), we measure the research output by the amount of acquired external funds. ${ }^{12}$ Assuming that the process of selection of grants works with a reasonable effectiveness, we can consider that external funds represent the "'market", value (or the society's valuation) of a university's research output. We distinguish

\footnotetext{
10 "Professors" include full and associate professors, "Lecturers" include assistant professors, lecturers and senior scientific staff. The category "Assistants" contains employed doctoral students and junior scientific staff such as post-doc assistants.

11 Furthermore, our proxy for the stock of real estate, the floor space, available for about half of the sample period shows relatively little variation over time, suggesting that assuming fixed real estate stock is not unrealistic.

12 Research funds can be considered as an intermediate output for a university. For further discussion of intermediate and final outputs see Agasisti and Pérez-Esparrells (2009) and Garcia-Aracil and Palomares-Montero (2010).
}

funds from the SNSF, a main body for financing fundamental research projects, and from other external funds that are mainly used for applied projects. More than half of the latter category stems from private sources (SFSO 2010b). The rest contains funds from the Swiss innovation promotion agency CTI, research mandates from the government, European and international research programs as well as income from services and continuing education. In this paper, all monetary values are deflated by the Swiss Consumer Price Index (CPI) to the year 2011.

A meaningful comparison of different universities should account for the quality aspects of the education and research activities. Quality aspects entail, however, complex factors that are difficult to measure. These factors are either unobservable such as the faculty's commitment and researchers' effort or prone to selection effects such as the initial ability of the admitted students. In this paper, department-level fixed effects can capture the unobserved time-invariant quality aspects. As seen in the previous section the model includes field-specific trends with random coefficients across departments. Our estimations indicated a considerably different trend in the two newly founded universities in the sample, namely the universities of Lugano and Lucerne. Founded in 1997, these universities indicate an initial rapid growth in terms of enrollments and other activities, which could not be handled with a random effect. Therefore, in the final specification we included a shift in linear and quadratic trend coefficients for these universities.

The data used in this study are based on various indicators of the Swiss higher education sector (see SFSO 2010b) for all Swiss university departments between 1995 to 2012. The data are organized into departments based on universities and scientific fields according to the SFSO classification. The SFSO classification divides the higher education sector into 16 departments organized in seven main scientific fields: the humanities, science, engineering, economics and business, law, medical sciences and the interdisciplinary fields. Generally, the actual organization of university departments is exactly similar to the SFSO classification with the difference that in some cases, a single SFSO department is split into multiple departments. An important exception is the case of interdisciplinary studies that is defined as a main field, but usually included in another school or department, depending on the university. Given the nonuniform definition of this field across universities and the difficulty to assign meaningful inputs and outputs, we exclude all interdisciplinary departments from our analysis. Therefore, we focus on fifteen departments organized in six fields (see Table 1).

After excluding a few observations with invalid and missing values, the final dataset consists of an unbalanced panel of 1723 observations from 103 university 
Table 1 Distribution of observations across universities and departments

\begin{tabular}{|c|c|c|}
\hline Name & Observations & Departments \\
\hline \multicolumn{3}{|l|}{ Universities } \\
\hline \multicolumn{3}{|l|}{ Federal universities } \\
\hline ETH Lausanne & 80 & 5 \\
\hline ETH Zurich & 182 & 11 \\
\hline \multicolumn{3}{|l|}{ Cantonal universities } \\
\hline University of Berne & 207 & 12 \\
\hline University of Basel & 198 & 11 \\
\hline University of Fribourg & 161 & 9 \\
\hline University of Geneva & 214 & 12 \\
\hline University of Lausanne & 165 & 10 \\
\hline University of Lucerne & 58 & 5 \\
\hline University of Neuchâtel & 158 & 9 \\
\hline University of St. Gallen & 39 & 3 \\
\hline University of Lugano & 63 & 5 \\
\hline University of Zurich & 198 & 11 \\
\hline Total & 1723 & 103 \\
\hline \multicolumn{3}{|l|}{ Scientific fields ${ }^{\mathrm{a}}$} \\
\hline \multicolumn{3}{|l|}{ Humanities: } \\
\hline Theology & 142 & 8 \\
\hline Linguistics and literature & 145 & 9 \\
\hline History and cultural studies & 155 & 9 \\
\hline Social sciences ${ }^{\mathrm{b}}$ & 174 & 11 \\
\hline Economics and business & 180 & 11 \\
\hline Law & 174 & 10 \\
\hline \multicolumn{3}{|l|}{ Science: } \\
\hline Mathematical and physical sciences ${ }^{\mathrm{c}}$ & 168 & 11 \\
\hline Natural sciences ${ }^{\mathrm{d}}$ & 162 & 9 \\
\hline \multicolumn{3}{|l|}{ Medical sciences: } \\
\hline Medicine & 107 & 6 \\
\hline Dentistry & 72 & 4 \\
\hline Veterinary medicine & 36 & 2 \\
\hline Pharmacology & 72 & 5 \\
\hline \multicolumn{3}{|l|}{ Engineering: } \\
\hline Architecture and geodesy & 68 & 4 \\
\hline Mechanical and electrical engineering & 50 & 3 \\
\hline Agricultural engineering and forestry & 18 & 1 \\
\hline Total & 1723 & 103 \\
\hline
\end{tabular}

a Based on SFSO (2010a)'s classification

b Social sciences include psychology, education, sociology, social work, cultural anthropology, political sciences and communication

c Also include computer science and astronomy

d Natural sciences include chemistry, biology, geoscience and geography departments distributed over 12 universities across a sample period of 18 years. The distribution of the observations across universities and departments is given in Table 1. In terms of number of departments humanities have the largest share with about $36 \%$, followed by science departments and medical schools with about $17 \%$, whereas economics, law and engineering represent the smallest shares each with about $10 \%$ of the sample.

Figure 1 shows the development of total inputs and outputs over the sample period (1995-2012) normalized by their 1995 values. As shown in Fig. 1a the highest growth among inputs occurred in nonlabor expenditures, 


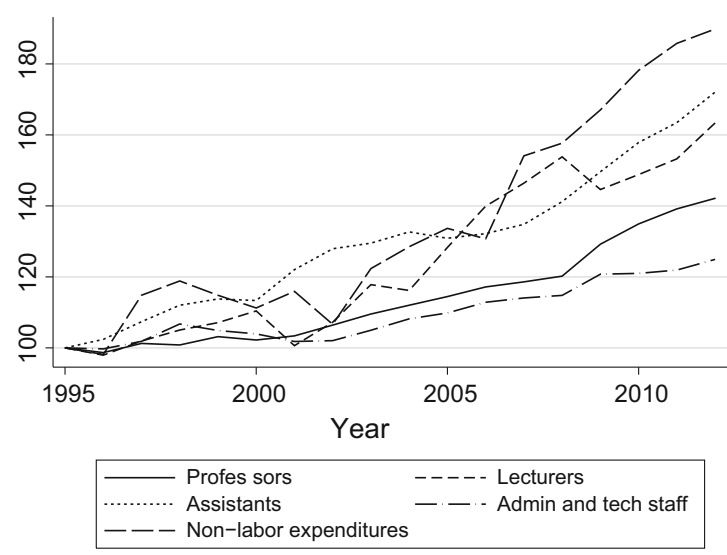

(a) Inputs

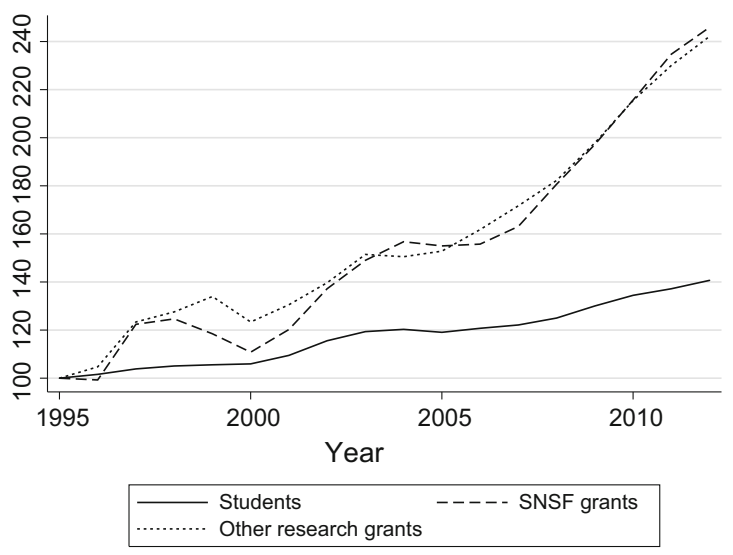

(b) Outputs

Fig. 1 Development of Swiss universities between 1995 and 2012 (numbers are total values indexed to 1995)

increasing by about $90 \%$ since 2001. Over the sample period nonacademic staff has grown about $20 \%$, whereas the academic staff (lecturers and assistants) has shown an important growth of $70 \%$. Figure $1 \mathrm{~b}$ shows a considerable difference in the growth of output measures over the sample period. While the number of students expanded by about $40 \%$, the corresponding growth in research grants reached more than $140 \%$.

Comparing the two graphs, one can observe a consistent pattern of growth in that the professor and student bodies show a similarly uniform growth amounting to about $40 \%$ over the sample period, whereas the research grants and nonlabor inputs have moved in a similar pattern, initially stagnating but picking up speed after year 2000 resulting in 140 and $90 \%$ growth by 2012. Considering an overall input growth of $20-90 \%$, the $140 \%$ growth in grants points to a considerable rise in productivity for research activities. However, enrollment rates have grown slower than most inputs, suggesting that the overall productivity development depends on how research and teaching activities enter the production process. The distance function approach allows us to assess growth in total factor productivity.

A descriptive summary of the variables included in the model along with the notation used for input/output variables are provided in Table 2. In a few departments one of the input/output variables (especially the external funds) can be zero in one or several periods, resulting in a zero value in about $5 \%$ of the sample. In order to accommodate the logarithmic form in the translog function we replaced these zero values by a negligible positive number, well below the corresponding smallest positive values observed in the sample. ${ }^{13}$ In addition to the main variables we also

\footnotetext{
13 We tried several alternative replacing values. The estimation results show little sensitivity. The final results reported in this paper
}

constructed two variables, which are used in alternative specifications of the distance function. In particular, we used the share of foreign (non-Swiss) students to proxy the department's international openness and a measure of diversity of the university's ongoing degree programs (share of Licentiate granted degrees and sum of squared shares for all 3 degrees) as proxies for the Bologna reform's progress in a given department. The analysis of variation of these proxies and their relation with productivity results will be discussed in Sect. 6 .

\section{Results}

\subsection{Estimation results}

The regression results for three alternative models are shown in Table 4. Model 1 shows a simple model with quadratic trends for the overall development and new universities, respectively. The overall trends have random coefficients on the department level. Model 2 tests whether quadratic trends are sufficient to capture the development over time by using cubic terms. Model 3, which is the main model used to estimate productivity, adds an autoregressive component of order one to the specification of Model 1 . Model 4 represents a variant of Models 3 including additional control variables, namely openness with respect to foreign students and a measure capturing the implementation rate of the Bologna reform in a quadratic form. Figure 5 displays the Malmquist productivity indices for all four

Footnote 13 continued

are based on replacing all zero values of inputs/outputs by 0.1 . The exact number of observations with zero values depends on the variable, varying from 6 for number of assistants to 82 for enrollments. 
Table 2 Summary statistics

\begin{tabular}{|c|c|c|c|c|c|c|c|c|}
\hline Variable & Definition & Mean & SD & Min & 25 th percentile & 50th percentile & 75th percentile & $\operatorname{Max}$ \\
\hline$y_{1}$ & Number of enrolled students & 847 & 859 & 0 & 220 & 600 & 1154 & 5220 \\
\hline$y_{2}$ & External funds from the $\mathrm{SNSF}^{\mathrm{a}}$ & 3640 & 5591 & 0 & 338 & 1094 & 3835 & 36,400 \\
\hline$y_{3}$ & Other external funds ${ }^{\mathrm{a}}$ & 6620 & 11,600 & 0 & 566 & 1935 & 6702 & 78,700 \\
\hline$x_{1}$ & Number of professors ${ }^{b}$ & 27 & 24 & 0.7 & 10 & 21 & 35 & 166 \\
\hline$x_{2}$ & Number of lecturers ${ }^{b}$ & 22 & 37 & 0 & 5 & 11 & 24 & 449 \\
\hline$x_{3}$ & Number of assistants ${ }^{\mathrm{b}}$ & 140 & 185 & 0 & 33 & 73 & 149 & 1229 \\
\hline$x_{4}$ & $\begin{array}{l}\text { Number of admin and technical } \\
\text { staff }^{b}\end{array}$ & 66 & 93 & 0 & 8 & 26 & 83 & 642 \\
\hline$x_{5}$ & Nonlabor expenditures $^{\mathrm{a}}$ & 10,800 & 23,100 & 0 & 1163 & 3229 & 9556 & 200,000 \\
\hline $\begin{array}{l}\text { International } \\
\text { openness }\end{array}$ & Share of foreign students & 0.24 & 0.16 & 0 & 0.12 & 0.20 & 0.33 & 1 \\
\hline $\begin{array}{l}\text { Bologna } \\
\text { penetration }\end{array}$ & Share of Bologna degrees & 0.29 & 0.41 & 0 & 0 & 0 & 0.72 & 1 \\
\hline
\end{tabular}

${ }^{a}$ In thousand 2011 Swiss Francs

b FTE full-time equivalent

models, revealing the robustness of our results across the specifications.

The regression results are generally plausible in the sense that the first-order output coefficients have a negative sign and the input coefficients are positive. Moreover, the distance functions' regularity conditions (increasing in input and decreasing in outputs) are satisfied in about $95 \%$ of the observations. The violation cases were limited to $5 \%$ of the sample. The only exception was the assistants input showing a negative marginal effect in $10 \%$ of the sample. The input coefficients can be interpreted as the corresponding input share in the distance function at the sample median. Considering model 3 , for instance, the results indicate a total share of $30.8 \%$ for lecturers and assistants, a small share of $6.9 \%$ for administrative staff and about $9.4 \%$ for nonlabor costs. Using the linear homogeneity condition the share of professors will amount to about $52.9 \%(.529=1-.101-.207-.069-.094)$ of resources.

The first-order output coefficients (Table 4) are output elasticities at the sample median. Again, considering model 3 as an example, the output coefficients suggest an elasticity of about 0.30 for teaching output (coefficient of $y_{1}$ ) as opposed to an elasticity of only 0.11 for research outputs (sum of the coefficients of $y_{2}$ and $y_{3}$ ). In terms of scale effects, the relatively low output elasticities (sum of 0.41 ) indicate increasing returns to scale, with a relatively high rate of economies of scale (about 0.59 at the sample median). This implies a substantial productivity gain due to scale effects, which is consistent with the findings reported by Olivares and Schenker-Wicki (2012) using a nonparametric approach. It is important to note that the estimated scale elasticities and the resulting productivity effects need to be considered in relation to the model's assumptions, especially regarding the omitted output characteristics such as teaching and research quality. The estimated input distance function assumes that such omitted variables can be captured by department fixed effects. In other words, the model relies on the assumption that temporal variations in quality factors have no correlation with temporal changes in outputs. This might be a restrictive assumption in the university context in which usually greater student body or research output might be combined with a higher level of quality. The estimated output elasticities also imply about three times higher elasticity for teaching compared to research outputs. In particular, these numbers suggest that $10 \%$ increase in students would require $3 \%$ more resources, whereas the same proportional increase in research output will require only marginally more than $1 \%$ overall increase in production factors. These results indicate the dominant weight of students as well as professors in the distance function. Note, however, that these numbers should be considered in light of the observed growth of various output/inputs. As shown in Fig. $1 \mathrm{~b}$, in the sample period, research grants have increased about three times more than students. Similarly the growth in mainly research-oriented staff (lectures/assistants) is about two times greater than that of professors. Considered together, these numbers point to a remarkable result: In the sample period, the productivity growth has been shared almost equally by research and education components of universities.

The standard deviation of the trend components is significant across models, suggesting a considerable heterogeneity across departments. The regressions also show a statistically significant autocorrelation coefficient, $\rho$, with a relatively high value of 0.594 . This suggests that the halflife of an inefficiency shock (fall to half of initial inefficiency) is about 1.3 years and the entire course of learning 
process (95\% adaptation) following a shock takes about 5.8 years. The coefficient's confidence interval remains below one, implying that our estimates are not affected by potential nonstationarity (unit root). In the two following paragraphs we will discuss the development of the Malmquist indices and their decomposition as well as scale effects and overall productivity based on model 3. Further discussion of productivity and its relationship with the Bologna reform and international openness based on model 4 will be presented in Sect. 6 .

\subsection{Malmquist index and its components}

Figure 2 displays the Malmquist productivity index and its components obtained from the main model (model 3). The graph represents the median values over all departments normalized to year 1995. The numerical values are also listed in Table 3. Regarding the overall development of productivity depicted in Fig. 2, our results suggest a fairly constant productivity until around 2000 followed by a fall in productivity. Overall, the model shows about $13 \%$ decrease in productivity between 1995 and 2012.

The results indicate a fairly stable productivity from 1995 to 2000, followed by a regress after 2000, with an annual rate of about $1 \%$ per year. As for changes in technical efficiency (Fig. 2), the results indicate that in the early period and the remaining years until about 2002, overall productivity gains can be attributed to changes in technical efficiency. Between 2002 and 2007, technical efficiency accentuated the negative technical change. However, the final decline after 2007 can be almost entirely attributed to technical change (an inward shift of the frontier), suggesting that inefficiency bears little responsibility at the end of the sample period.

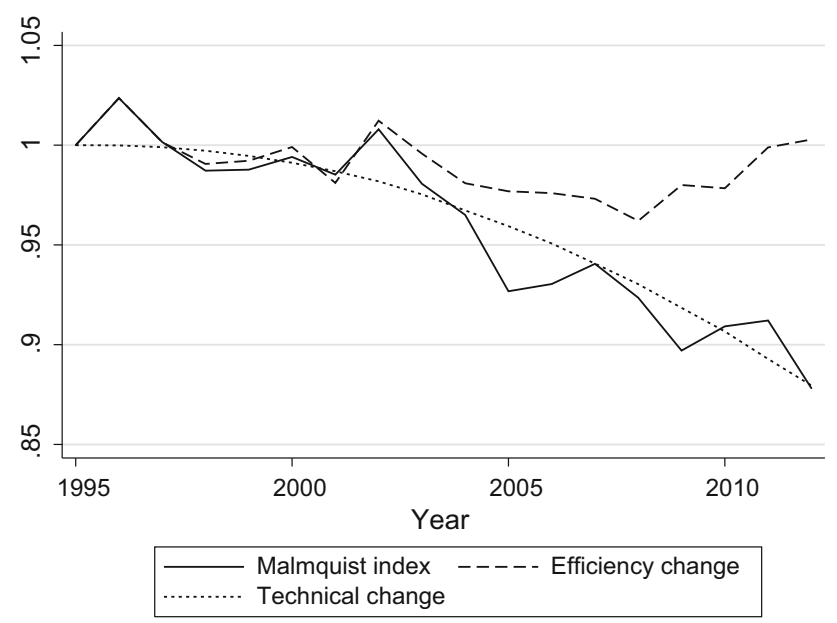

Fig. 2 Malmquist productivity index and its components based on median values indexed to 1995
Table 3 Overall productivity index and its components based on model with autoregressive efficiency term (Model 3)

\begin{tabular}{|c|c|c|c|c|c|c|c|}
\hline Unit & Index & 1997 & 2000 & 2003 & 2006 & 2009 & 2012 \\
\hline Total & TFP & 1.03 & 0.99 & 1.00 & 1.02 & 1.05 & 1.02 \\
\hline Humanities & TFP & 1.05 & 1.08 & 1.13 & 1.05 & 1.06 & 0.90 \\
\hline Economics & TFP & 0.91 & 0.85 & 0.89 & 0.97 & 1.16 & 0.94 \\
\hline Law & TFP & 0.95 & 0.91 & 0.91 & 0.81 & 0.83 & 0.91 \\
\hline Science & TFP & 1.19 & 1.12 & 1.14 & 1.34 & 1.33 & 1.45 \\
\hline Medicine & TFP & 0.98 & 0.83 & 0.81 & 0.78 & 0.80 & 0.83 \\
\hline Engineering & TFP & 0.89 & 0.89 & 0.77 & 0.96 & 1.00 & 1.11 \\
\hline Total & SE & 1.00 & 0.99 & 1.05 & 1.09 & 1.17 & 1.20 \\
\hline Humanities & SE & 1.03 & 1.05 & 1.14 & 1.17 & 1.26 & 1.23 \\
\hline Economics & SE & 0.98 & 0.96 & 1.03 & 1.03 & 1.07 & 1.07 \\
\hline Law & SE & 0.97 & 0.95 & 1.03 & 1.00 & 1.03 & 1.03 \\
\hline Science & SE & 1.03 & 1.04 & 1.09 & 1.15 & 1.18 & 1.31 \\
\hline Medicine & SE & 0.95 & 0.87 & 0.90 & 0.98 & 1.07 & 1.12 \\
\hline Engineering & SE & 1.00 & 0.97 & 0.92 & 1.04 & 1.24 & 1.38 \\
\hline Total & M & 1.01 & 0.99 & 0.98 & 0.94 & 0.91 & 0.89 \\
\hline Humanities & M & 1.01 & 1.03 & 1.00 & 0.96 & 0.92 & 0.90 \\
\hline Economics & M & 1.00 & 0.93 & 0.90 & 0.89 & 0.92 & 0.88 \\
\hline Law & M & 0.97 & 0.98 & 1.03 & 0.98 & 0.81 & 0.88 \\
\hline Science & M & 1.02 & 1.06 & 1.07 & 1.05 & 1.06 & 0.98 \\
\hline Medicine & M & 1.06 & 0.92 & 0.91 & 0.79 & 0.80 & 0.79 \\
\hline Engineering & M & 0.91 & 0.86 & 0.86 & 0.84 & 0.86 & 0.83 \\
\hline Total & $\mathrm{T}$ & 1.00 & 0.99 & 0.97 & 0.94 & 0.91 & 0.86 \\
\hline Humanities & $\mathrm{T}$ & 1.00 & 0.99 & 0.97 & 0.94 & 0.90 & 0.86 \\
\hline Economics & $\mathrm{T}$ & 1.00 & 0.99 & 0.97 & 0.95 & 0.92 & 0.88 \\
\hline Law & $\mathrm{T}$ & 1.00 & 0.98 & 0.95 & 0.90 & 0.85 & 0.78 \\
\hline Science & $\mathrm{T}$ & 1.00 & 0.99 & 0.98 & 0.97 & 0.94 & 0.91 \\
\hline Medicine & $\mathrm{T}$ & 1.00 & 0.99 & 0.97 & 0.93 & 0.88 & 0.83 \\
\hline Engineering & $\mathrm{T}$ & 1.00 & 0.99 & 0.99 & 0.97 & 0.96 & 0.93 \\
\hline Total & $\mathrm{TE}$ & 1.01 & 1.00 & 0.99 & 0.98 & 0.98 & 0.99 \\
\hline Humanities & $\mathrm{TE}$ & 1.01 & 1.03 & 1.01 & 0.98 & 1.00 & 1.03 \\
\hline Economics & TE & 1.00 & 0.96 & 0.97 & 0.98 & 0.97 & 0.97 \\
\hline Law & TE & 0.97 & 1.00 & 1.00 & 0.97 & 1.00 & 0.95 \\
\hline Science & $\mathrm{TE}$ & 1.02 & 1.07 & 1.08 & 1.10 & 1.04 & 1.01 \\
\hline Medicine & $\mathrm{TE}$ & 1.06 & 0.95 & 0.95 & 0.89 & 0.89 & 0.94 \\
\hline Engineering & TE & 0.91 & 0.86 & 0.82 & 0.87 & 0.92 & 0.94 \\
\hline
\end{tabular}

The table displays TFP, indices for the overall productivity; SE, scale effects; M, Malmquist; T, technical change; TE, efficiency change

The indices are set equal to 1 in 1995

The numbers listed in the table are the median values of individual estimates

Figure 3 displays the median development of the Malmquist index, scale effects and the overall TFP index. The picture diverts substantially from the developments in the Malmquist index. While scale effects have been small until about 2000, the growth of universities thereafter suggested substantial scale effects. In total, these positive scale effects make up for the negative development in the 


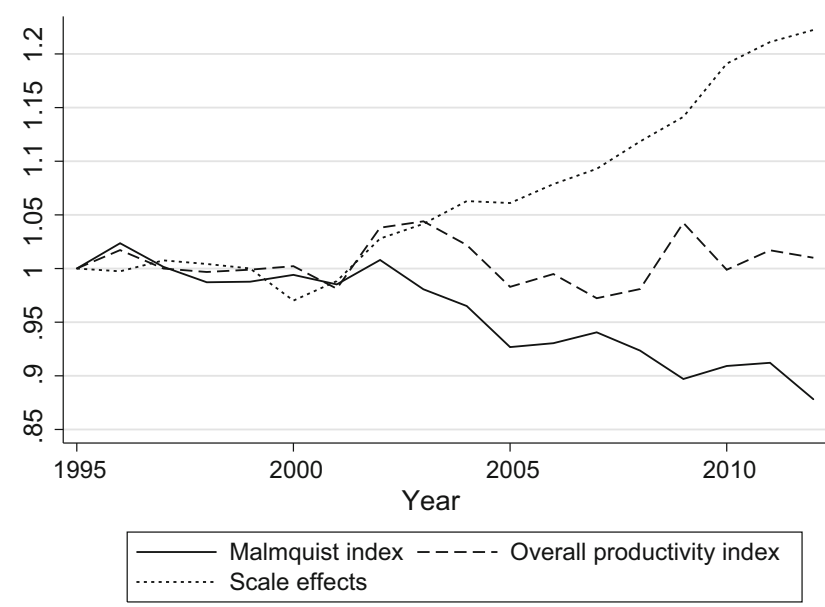

Fig. 3 Malmquist productivity index, scale effects and overall productivity index based on median values indexed to 1995

Malmquist index, resulting in a more or less constant estimate of overall TFP growth.

The details of numerical results based on median values by scientific field are listed in Table 3 . These results reveal substantial heterogeneity in the development across scientific fields. The TFP index shows an overall growth for science and engineering and a decline in the humanities, economics, law and medicine. The patterns of productivity gain due to scale effects across scientific fields suggest a considerable growth across all branches with a similar pattern. Namely, science and engineering show the best performance, while medicine and law have the lowest productivity gain. Our analysis also indicates that the scale effects are quite heterogeneous across departments within scientific fields. The generally observed pattern also points to an overall decline in the Malmquist index. The only exception is science departments that show a small increase. The most pronounced decline in the Malmquist index has occurred in medicine.

Overall, excepting science departments, the estimated productivity trends are not entirely consistent with the hypothesis about positive effects of globalization. However, we do observe a systematic difference between fields like medicine and law that can be considered as location specific with others like science and engineering that have fairly universal features at the other extreme.

In the case of medical departments, part of the decline might be associated with the increasing resources used in university hospitals. However, due to the difficulties in separating educational and clinical resources (see, e.g., Kempkes and Pohl 2010), this explanation should be considered with caution. It is interesting to note that according to our results medical departments show not only one of the lowest productivity performance, but also show the highest sudden fall of productivity incidentally occurring between
2003 and 2004 (Table 3), corresponding to the outset of effective implementation of Bologna reforms in Switzerland. It is worth noting that given the special structure of medical training (a primary physician diploma typically after 5 or 6 years), it can be assumed that the reforms have put a relatively great adaptation burden on medical departments. ${ }^{14}$

Table 3 further allows to compare the development of scale effects across scientific fields, suggesting that scale effects have been positive in all fields, but largest in economics, science and engineering. As a result, TFP growth has been outstanding in science, followed by approximately neutral TFP growth in medicine and engineering. Economics and law display a small decline in overall productivity, while the decline is steeper in Humanities.

We also analyzed the productivity development across different universities. However, because of the great variety among universities regarding size and department mix, we could not detect any conclusive evidence for significant productivity differences across universities. In general, the observed patterns may be equally well explained by differences in specialization. This is particularly the case for relatively small universities. For instance, the estimated trends appear to suggest a substantial productivity growth for the departments in the university of Lucerne and Lugano (the two newly founded universities) and a relatively steep decline in departments of the ETH Lausanne and the university of Lausanne. But, with the exception of the university of Lausanne, these universities consist of only a few departments belonging to diverse fields with presumably different productivity growths. The universities of Zurich and Basel have relatively low TFP declines, while the universities of Berne and Geneva display a steeper decline. The universities of Neuchâtel, Fribourg and the ETH Zurich show a more or less constant productivity over the sample period. Overall, the variations in productivity growth could be associated with fields of specialization rather than differences among universities. This observation is consistent with the relatively low estimated share of technical efficiency in productivity growth. In other words it is not the managerial differences at the university level but the structural differences between disciplines and their development that drive a major part of variation in TFP growth in particular the gains due to scale effects.

\footnotetext{
${ }^{14}$ In fact medical schools throughout Europe have more or less ardently resisted Bologna reforms (Patricio et al. 2012). Switzerland's medical schools stand out as an exception that integrated Bachelor degrees in their programs (Michaud 2012). The 3-year Bachelor program can be a step toward a Master degree in medicine (physician diploma) but also could lead to other careers.
} 


\section{International openness and the Bologna reform}

In this section we examine possible impacts of the Bologna reform and openness to international students on the productivity estimates reported in Sect. 5. We measure openness by the share of enrolled foreign students. As shown in Fig. 4 after a stagnation period before 2000, the share of foreign students has considerably grown from about $19 \%$ in 2000 to nearly $30 \%$ in 2012. In terms of number of international students, this amounts to an average growth of $7 \%$ per year. This pattern is consistent with a main objective of the Bologna reform, namely student mobility.

Figure 4 also displays a measure of the degree of implementation of the Bologna reform. "Bologna Penetration" is the share of new-regime degrees (Bachelor and Master), divided by total granted nondoctoral degrees (Licentiate, Bachelor and Master). As the reform takes effect, the Bologna measure develops at a similar rate on average, but showing different patterns of development among various universities. Figure 4 shows that after the first graduations according to the new system in 2003, the share of Bologna degrees has a steep increase. Since the universities were given a deadline for the complete implementation of the reform in 2010, one expects to observe a small share of old-regime degrees. As shown in Fig. 4, though the average share exceeds $90 \%$, the old-regime degrees still exist in 2012. This is partly because of the slow implementation but also due to the offered option to new students (until late into the course of the reform) to choose between the old and new regimes. This flexibility combined with gradual changes in the courses offered in Licentiate programs required the simultaneous organization and functioning of at least several transitional systems.

One may expect that through harmonization the reforms create a better environment for competition and globalization, hence an increase in productivity. However, considering the additional resources to implement these systems, one can expect a negative effect on productivity, which implies in the distance function, a negative effect for Bologna Penetration. ${ }^{15}$ In fact, the striking similarity between development of Bologna variables in Fig. 4 and the productivity decline depicted in Fig. 2 points to the implementation burden of reforms as a responsible for the estimated decline in productivity.

However, the regression results indicate no statistically significant effects for the Bologna variable, suggesting that neither one of the competing hypotheses can be favored.

Similarly, we expect that internationalization should have positive spillovers thus increasing productivity (a positive coefficient in the distance function). On the other hand, openness to international students implies a greater number of English language programs and courses, generally offered

\footnotetext{
15 A positive sign implies that an increase in diversity has a positive impact on productivity.
}

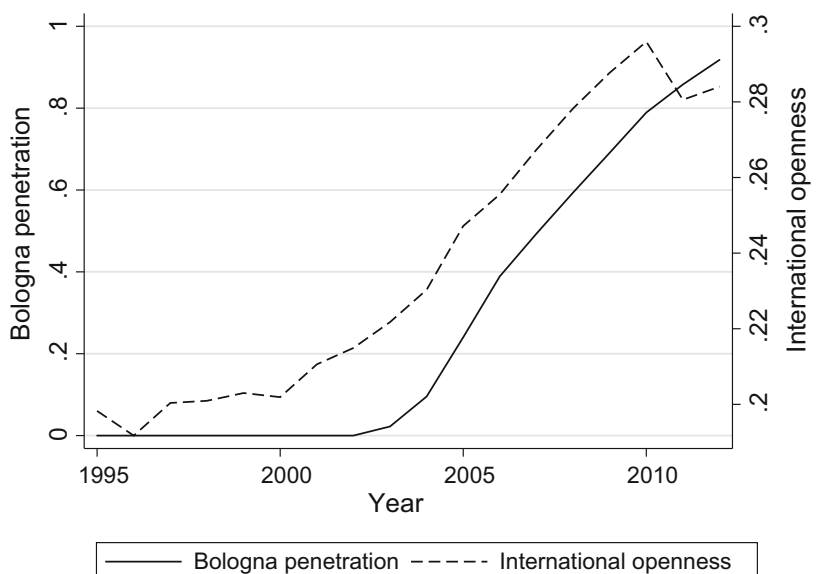

Fig. 4 Overall trends of openness and the penetration of the Bologna reform

at the graduate level. The estimated effect of openness in Model 4 is negative but statistically insignificant (Table 4).

A careful comparison of the graphs in Figs. 1, 2, 3 and 4 indicates a recurring pattern of remarkable change of trends in the period between 2000 and 2002. That period coincides with the outset of the Bologna reform, but it is also characterized by an increasing rate of growth in research grants and intermediary scientific staff (lecturers) as well as universities' nonlabor expenditures and share of students coming from abroad. Overall, these developments point to a gradual change in Switzerland's university landscape with an increasing shift to research and external funding as well as internationalization. Our analysis indicates that these changes coincided with a gradual decline in productivity growth. Our results do not favor any significant impact from Bologna reform or internationalization. This result is in contrast to Agasisti and Bolli (2013)'s finding, namely a productivity-enhancing impact for Bologna reform. This difference can be explained by richer specification of temporal effects in this paper, which could capture much of the dynamic variation. Another important difference is in the output distance approach used by Agasisti and Bolli (2013), which relies on the exogeneity of input factors. Neither study considers the possible interaction effects between Bologna reform penetration and the extent of the economies scale. The importance of scale effects highlighted in this study suggests that an adequate analysis of Bologna impacts needs to account for the resulting structural changes on the scale characteristics of the university's production function.

\section{Conclusions}

We proposed a panel data model to estimate Malmquist productivity index in the presence of strong unobserved heterogeneity. Similar to previous studies by Fuentes et al. 
(2001) and Atkinson et al. (2003), we use a parametric distance function that combines the benefits of a parametric methodology in panel data with the intuitive advantages of the Malmquist index as a discrete measure of productivity. Individual fixed effects are used to model heterogeneity among production units in time-invariant factors, hence decreasing the potentially important biases due to unobserved factors. Such factors are especially important in applications such as universities where the quality aspects are complex and difficult to measure. In addition, the proposed model uses random coefficients to account for heterogeneity in productivity growth. Therefore, the productivity measures vary not only by observed quantities but also by idiosyncratic factors specific to individual production units. Finally, the dynamic structure of inefficiency shocks and their dissipation through adaptation and learning are captured by an autoregressive stochastic term.

We applied the model to a panel data set from one hundred Swiss university departments to analyze the dynamics of productivity from 1995 to 2012. The analysis is based on department-level data with specific outputs, namely students and external funds. We assumed that the temporal variations in other outputs like faculty's publication record and quality of research output are reflected in the departments' success or failure in attracting external funds. The results point to a negative trend in the Malmquist productivity index, following a reversal about year 2000 , with an average decline of about $1 \%$ per year. Our decomposition analysis suggests that the observed decline in the Malmquist index could be attributed to a negative technical change rather than to inefficiency.

The negative trend in the Malmquist index ignores the potential economies of scale arising due to the growth university departments have experienced in the observation period. Accounting for these scale effects, Orea (2002) suggests that overall productivity development has been about constant. The opposing trends in Malmquist and scale effects yield an overall stagnation over the sample period. However, it is important to note that our estimation of scale effects relies on a possibly restrictive assumption that the temporal observed changes in outputs are not correlated with temporal variations in omitted variables such as various quality aspects of universities' research and teaching activities. To the extent that expanding departments have achieved a simultaneous quality improvement, our model would probably overestimate scale effects.

We analyzed the heterogeneity in the estimated trends across scientific fields and universities. The results while pointing to substantial differences across scientific fields do not favor considerable differences across universities. This pattern suggests that the sources of productivity differences are probably related to specific developments in each field rather than managerial differences among universities. The results indicate a considerable variation across scientific fields. Medicine and Law have the strongest decline in Malmquist indices, while science and engineering departments perform the best with nearly constant Malmquist indices. Scale effects have been most pronounced in economics, science and engineering, resulting in an outstanding performance of science departments followed by engineering, in terms of TFP growth. Accounting for scale effects also suggests that TFP growth has been lowest in medicine and law.

In contrast to Agasisti and Bolli (2013) our findings do not indicate any significant relationship between productivity and variables representing the Bologna reform's penetration and internationalization. Our analysis suggests that the estimated reforms' effects could be sensitive to the specification of heterogeneity across time and the model's input/output orientation. Moreover, the importance of scale effects highlighted in our analysis indicates that further research should address the possible impacts of reforms on the possibility of realization of the economies of scale.

This study proposes a novel approach with certain flexibilities in modeling unobserved heterogeneity in the estimation changes in productivity and efficiency. Using the new methodology for the first time in the higher education sector, the analysis faces a number of limitations that should be considered in drawing any policy conclusions. In particular, the available data do not allow any control for potential developments in quality aspects in universities teaching and research activities. The time-invariant components of these unobservable factors are essentially captured by the individual fixed effects included in the model. Possible correlations between the timevarying components of unobservables with the included inputs and outputs might induce estimation biases. Moreover, the available proxies for capital inputs entail a measurement error due to nonuniform accounting practices across universities. Last but not least, the adopted model assumes the neutrality of technological change, hence abstracting from possible interactions between scale characteristics and technical change. As emphasized by our findings, there is a need for further research and analysis for identifying productivity components in a context where organizational reforms can bring about structural changes with simultaneous effects on both scale characteristics and technical change.

Acknowledgments We would like to thank the Swiss Federal Statistical Office (SFSO) for providing the data and acknowledge the exceptional support we received from their higher education manager, Petra Koller. We are grateful to Lionel Perini, Alain Schatt, Milad Zarin and four anonymous referees for their helpful suggestions. We 
also thank the participants of the Halle Workshop on Efficiency and Productivity Analysis, 2010, and the European Workshop on Productivity and Efficiency Analysis, 2011, for their comments on earlier versions.

\section{Appendix}

See Table 4 and Fig. 5.
Table 4 Parameter estimates of the input distance function

\begin{tabular}{|c|c|c|c|c|}
\hline$N=1723$ & Model 1 & Model 2 & Model 3 & Model 4 \\
\hline$y_{1}$ & $\begin{array}{l}-0.254 * * * \\
(0.022)\end{array}$ & $\begin{array}{l}-0.231 * * * \\
(0.023)\end{array}$ & $\begin{array}{l}-0.303 * * * \\
(0.026)\end{array}$ & $\begin{array}{l}-0.306^{* * *} \\
(0.026)\end{array}$ \\
\hline$y_{2}$ & $\begin{array}{l}-0.070^{* * *} \\
(0.007)\end{array}$ & $\begin{array}{l}-0.069^{* * * *} \\
(0.007)\end{array}$ & $\begin{array}{l}-0.052 * * * \\
(0.007)\end{array}$ & $\begin{array}{l}-0.052 * * * \\
(0.007)\end{array}$ \\
\hline$y_{3}$ & $\begin{array}{l}-0.053 * * * \\
(0.006)\end{array}$ & $\begin{array}{l}-0.053^{* * * *} \\
(0.006)\end{array}$ & $\begin{array}{l}-0.060^{* * *} \\
(0.006)\end{array}$ & $\begin{array}{l}-0.060 * * * \\
(0.006)\end{array}$ \\
\hline$y_{1} y_{1}$ & $\begin{array}{l}-0.030^{* * * *} \\
(0.005)\end{array}$ & $\begin{array}{l}-0.026^{* * * *} \\
(0.005)\end{array}$ & $\begin{array}{l}-0.040^{* * *} \\
(0.005)\end{array}$ & $\begin{array}{l}-0.041^{* * *} \\
(0.005)\end{array}$ \\
\hline$y_{2} y_{2}$ & $\begin{array}{l}-0.006^{* * * *} \\
(0.001)\end{array}$ & $\begin{array}{l}-0.006^{* * * *} \\
(0.001)\end{array}$ & $\begin{array}{l}-0.004 * * * \\
(0.001)\end{array}$ & $\begin{array}{l}-0.004^{* * * *} \\
(0.001)\end{array}$ \\
\hline$y_{3} y_{3}$ & $\begin{array}{l}-0.005^{* * * *} \\
(0.001)\end{array}$ & $\begin{array}{l}-0.005^{* * * *} \\
(0.001)\end{array}$ & $\begin{array}{l}-0.006^{* * * *} \\
(0.001)\end{array}$ & $\begin{array}{l}-0.006^{* * * *} \\
(0.001)\end{array}$ \\
\hline$y_{1} y_{2}$ & $\begin{array}{l}0.000 \\
(0.001)\end{array}$ & $\begin{array}{l}0.000 \\
(0.001)\end{array}$ & $\begin{array}{l}0.000 \\
(0.001)\end{array}$ & $\begin{array}{l}0.001 \\
(0.001)\end{array}$ \\
\hline$y_{1} y_{3}$ & $\begin{array}{l}0.007 * * * \\
(0.002)\end{array}$ & $\begin{array}{l}0.008 * * * \\
(0.002)\end{array}$ & $\begin{array}{l}0.002 \\
(0.002)\end{array}$ & $\begin{array}{l}0.002 \\
(0.002)\end{array}$ \\
\hline$y_{2} y_{3}$ & $\begin{array}{l}0.000 \\
(0.001)\end{array}$ & $\begin{array}{l}0.000 \\
(0.000)\end{array}$ & $\begin{array}{l}0.001 * * * \\
(0.000)\end{array}$ & $\begin{array}{l}0.001 * * * \\
(0.000)\end{array}$ \\
\hline$x_{2}$ & $\begin{array}{l}0.098 * * * \\
(0.008)\end{array}$ & $\begin{array}{l}0.099 * * * \\
(0.009)\end{array}$ & $\begin{array}{l}0.101 * * * \\
(0.009)\end{array}$ & $\begin{array}{l}0.101 * * * \\
(0.009)\end{array}$ \\
\hline$x_{3}$ & $\begin{array}{l}0.197 * * * \\
(0.018)\end{array}$ & $\begin{array}{l}0.192 * * * \\
(0.019)\end{array}$ & $\begin{array}{l}0.207 * * * \\
(0.019)\end{array}$ & $\begin{array}{l}0.208 * * * \\
(0.019)\end{array}$ \\
\hline$x_{4}$ & $\begin{array}{l}0.068 * * * \\
(0.015)\end{array}$ & $\begin{array}{l}0.065 * * * \\
(0.015)\end{array}$ & $\begin{array}{l}0.069 * * * \\
(0.016)\end{array}$ & $\begin{array}{l}0.070 * * * \\
(0.016)\end{array}$ \\
\hline$x_{5}$ & $\begin{array}{l}0.099 * * * \\
(0.011)\end{array}$ & $\begin{array}{l}0.102 * * * \\
(0.010)\end{array}$ & $\begin{array}{l}0.094 * * * \\
(0.010)\end{array}$ & $\begin{array}{l}0.093 * * * \\
(0.010)\end{array}$ \\
\hline$x_{2} x_{2}$ & $\begin{array}{l}0.032 * * * \\
(0.006)\end{array}$ & $\begin{array}{l}0.031 * * * \\
(0.006)\end{array}$ & $\begin{array}{l}0.036 * * * \\
(0.006)\end{array}$ & $\begin{array}{l}0.036 * * * \\
(0.006)\end{array}$ \\
\hline$x_{3} x_{3}$ & $\begin{array}{l}0.207 * * * \\
(0.024)\end{array}$ & $\begin{array}{l}0.216 * * * \\
(0.024)\end{array}$ & $\begin{array}{l}0.238 * * * \\
(0.023)\end{array}$ & $\begin{array}{l}0.238 * * * \\
(0.023)\end{array}$ \\
\hline$x_{4} x_{4}$ & $\begin{array}{l}0.029 * * * \\
(0.007)\end{array}$ & $\begin{array}{l}0.027 * * * \\
(0.007)\end{array}$ & $\begin{array}{l}0.026 * * * \\
(0.007)\end{array}$ & $\begin{array}{l}0.026^{* * *} \\
(0.007)\end{array}$ \\
\hline$x_{5} x_{5}$ & $\begin{array}{l}-0.017 * * * \\
(0.004)\end{array}$ & $\begin{array}{l}-0.015^{* * * *} \\
(0.004)\end{array}$ & $\begin{array}{l}-0.019 * * * \\
(0.004)\end{array}$ & $\begin{array}{l}-0.019 * * * \\
(0.004)\end{array}$ \\
\hline$x_{2} x_{3}$ & $\begin{array}{l}-0.074 * * * \\
(0.009)\end{array}$ & $\begin{array}{l}-0.073^{* * * *} \\
(0.009)\end{array}$ & $\begin{array}{l}-0.077 * * * \\
(0.009)\end{array}$ & $\begin{array}{l}-0.077 * * * \\
(0.009)\end{array}$ \\
\hline$x_{2} x_{4}$ & $\begin{array}{l}0.013 * * \\
(0.006)\end{array}$ & $\begin{array}{l}0.013 * * \\
(0.006)\end{array}$ & $\begin{array}{l}0.010^{*} \\
(0.006)\end{array}$ & $\begin{array}{l}0.009 * \\
(0.006)\end{array}$ \\
\hline$x_{2} x_{5}$ & $\begin{array}{l}0.001 \\
(0.003)\end{array}$ & $\begin{array}{l}0.002 \\
(0.003)\end{array}$ & $\begin{array}{l}0.001 \\
(0.003)\end{array}$ & $\begin{array}{l}0.002 \\
(0.003)\end{array}$ \\
\hline$x_{3} x_{4}$ & $\begin{array}{l}0.017 \\
(0.012)\end{array}$ & $\begin{array}{l}0.013 \\
(0.012)\end{array}$ & $\begin{array}{l}0.008 \\
(0.012)\end{array}$ & $\begin{array}{l}0.008 \\
(0.012)\end{array}$ \\
\hline$x_{3} x_{5}$ & $\begin{array}{l}0.023 * * * \\
(0.006)\end{array}$ & $\begin{array}{l}0.023 * * * \\
(0.006)\end{array}$ & $\begin{array}{l}0.036 * * * \\
(0.006)\end{array}$ & $\begin{array}{l}0.036 * * * \\
(0.006)\end{array}$ \\
\hline$x_{4} x_{5}$ & -0.001 & 0.001 & $-0.008 * * *$ & $-0.008 * * *$ \\
\hline
\end{tabular}


Table 4 continued

\begin{tabular}{|c|c|c|c|c|}
\hline$N=1723$ & Model 1 & Model 2 & Model 3 & Model 4 \\
\hline & $(0.003)$ & $(0.003)$ & $(0.003)$ & $(0.003)$ \\
\hline \multirow[t]{2}{*}{$x_{2} y_{1}$} & $-0.011 * * *$ & $-0.010 * * *$ & $-0.012 * * *$ & $-0.012 * * *$ \\
\hline & $(0.002)$ & $(0.002)$ & $(0.002)$ & $(0.002)$ \\
\hline \multirow[t]{2}{*}{$x_{2} y_{2}$} & 0.003 & 0.003 & 0.001 & 0.001 \\
\hline & $(0.002)$ & $(0.002)$ & $(0.002)$ & $(0.002)$ \\
\hline \multirow[t]{2}{*}{$x_{2} y_{3}$} & $0.004 *$ & $0.004 *$ & $0.009 * * *$ & $0.009 * * *$ \\
\hline & $(0.002)$ & $(0.002)$ & $(0.002)$ & $(0.002)$ \\
\hline \multirow[t]{2}{*}{$x_{3} y_{1}$} & $0.043 * * *$ & $0.042 * * *$ & $0.051 * * *$ & $0.051 * * *$ \\
\hline & $(0.006)$ & $(0.006)$ & $(0.005)$ & $(0.005)$ \\
\hline \multirow[t]{2}{*}{$x_{3} y_{2}$} & $-0.008 * * *$ & $-0.009 * * *$ & $-0.015 * * *$ & $-0.015^{* * *}$ \\
\hline & $(0.003)$ & $(0.003)$ & $(0.003)$ & $(0.003)$ \\
\hline \multirow[t]{2}{*}{$x_{3} y_{3}$} & $-0.011 * *$ & $-0.012 * * *$ & $-0.019 * * *$ & $-0.019 * * *$ \\
\hline & $(0.005)$ & $(0.005)$ & $(0.004)$ & $(0.004)$ \\
\hline \multirow[t]{2}{*}{$x_{4} y_{1}$} & -0.005 & $-0.006^{*}$ & $-0.007 * *$ & $-0.007 * *$ \\
\hline & $(0.003)$ & $(0.003)$ & $(0.003)$ & $(0.003)$ \\
\hline \multirow[t]{2}{*}{$x_{4} y_{2}$} & $0.005 * *$ & $0.005 * *$ & $0.008 * * *$ & $0.008 * * *$ \\
\hline & $(0.002)$ & $(0.002)$ & $(0.002)$ & $(0.002)$ \\
\hline \multirow[t]{2}{*}{$x_{4} y_{3}$} & -0.001 & -0.000 & 0.001 & 0.001 \\
\hline & $(0.001)$ & $(0.001)$ & $(0.001)$ & $(0.001)$ \\
\hline \multirow[t]{2}{*}{$x_{5} y_{1}$} & $-0.007 * * *$ & $-0.007 * * *$ & $-0.004 * *$ & $-0.004 * *$ \\
\hline & $(0.002)$ & $(0.002)$ & $(0.002)$ & $(0.002)$ \\
\hline \multirow[t]{2}{*}{$x_{5} y_{2}$} & $0.008 * * *$ & $0.007 * * *$ & $0.006 * * *$ & $0.006 * * *$ \\
\hline & $(0.002)$ & $(0.002)$ & $(0.002)$ & $(0.002)$ \\
\hline \multirow[t]{2}{*}{$x_{5} y_{3}$} & $0.006 * * *$ & $0.006 * * *$ & $0.008 * * *$ & $0.008 * * *$ \\
\hline & $(0.002)$ & $(0.002)$ & $(0.002)$ & $(0.002)$ \\
\hline \multirow[t]{2}{*}{ New_lin } & 0.018 & $0.171 * * *$ & $0.051 * *$ & $0.051 * *$ \\
\hline & $(0.020)$ & $(0.044)$ & $(0.021)$ & $(0.021)$ \\
\hline \multirow[t]{2}{*}{ New_squ } & $-0.001^{*}$ & $-0.019 * * *$ & $-0.003 * * *$ & $-0.003 * * *$ \\
\hline & $(0.001)$ & $(0.004)$ & $(0.001)$ & $(0.001)$ \\
\hline \multirow[t]{2}{*}{ New_cub } & & $0.001 * * *$ & & \\
\hline & & $(0.000)$ & & \\
\hline \multirow[t]{2}{*}{ Trend_lin } & 0.000 & 0.005 & 0.000 & 0.001 \\
\hline & $(0.004)$ & $(0.006)$ & $(0.003)$ & $(0.003)$ \\
\hline \multirow[t]{2}{*}{ Trend_squ } & $-0.001 * * *$ & $-0.001 * *$ & $-0.001 * *$ & $-0.001 * *$ \\
\hline & $(0.000)$ & $(0.001)$ & $(0.000)$ & $(0.000)$ \\
\hline \multirow[t]{2}{*}{ Trend_cub } & & 0.000 & & \\
\hline & & $(0.000)$ & & \\
\hline \multirow[t]{2}{*}{ International openness } & & & & -0.073 \\
\hline & & & & $(0.070)$ \\
\hline \multirow[t]{2}{*}{ Bologna penetration } & & & & 0.001 \\
\hline & & & & $(0.047)$ \\
\hline \multirow[t]{2}{*}{ Bologna penetration_squ } & & & & 0.008 \\
\hline & & & & $(0.047)$ \\
\hline \multicolumn{5}{|l|}{ Random effects } \\
\hline sd(trend_lin) & $0.032 * * *$ & $0.032 * * *$ & $9 * 10^{12}$ & $3 * 10^{13}$ \\
\hline & $(0.004)$ & $(0.003)$ & $\left(3 * 10^{11}\right)$ & $\left(7 * 10^{13}\right)$ \\
\hline sd(trend_squ) & $0.001 * * *$ & 0.0002 & $0.001 * * *$ & $0.001 * * *$ \\
\hline & $(0.0002)$ & $(0.001)$ & $(0.0001)$ & $(0.0001)$ \\
\hline
\end{tabular}


Table 4 continued

\begin{tabular}{lllll}
\hline$N=1723$ & Model 1 & Model 2 & Model 3 & Model 4 \\
\hline sd(trend_cub) & & $0.00006 * * *$ \\
$\left(8 * 10^{6}\right)$ & & \\
Autocorrelation & & & \\
$\rho$ & & & $0.594 * * *$ & $0.592 * * *$ \\
& & $(0.038)$ & $(0.027)$ \\
$\mathrm{N}$ & 1723 & 1723 & 1723 & 1723 \\
\hline
\end{tabular}

Standard errors in parentheses

All models include department fixed effects

All models have random coefficients on time trends

Model 2 includes cubic terms of time trends

Models 3 and 4 assume an autoregressive error term

Model 4 includes additional control variables for international openness and the implementation of the Bologna reform

Inputs, $x$, and outputs, $y$, are in logs and normalized by their corresponding median values

Coefficients of terms with the input variable, $x_{1}$, can be obtained by the linear homogeneity constraints (see footnote 7)

The dependent variable is $-x_{1}$

Inputs: professors $\left(x_{1}\right)$, lecturers $\left(x_{2}\right)$, assistants $\left(x_{3}\right)$, administrative staff $\left(x_{4}\right)$, nonlabor expenditures $\left(x_{5}\right)$ Outputs: students $\left(y_{1}\right)$, SNSF research grants $\left(y_{2}\right)$, other research grants $\left(y_{3}\right)$

$*, * *$ and $* * *$ denote significance at 10,5 and $1 \%$, respectively

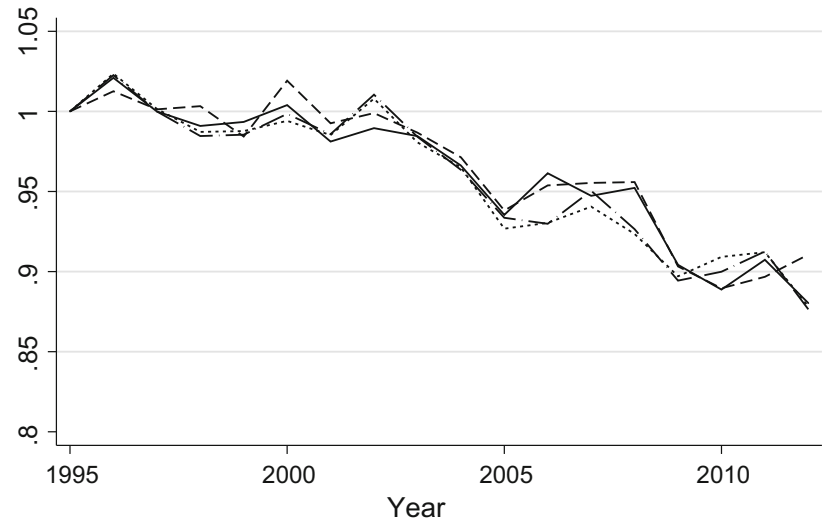

Malmquist Index Model 1 - - - - Malmquist Index Model 2 Malmquist Index Model 3 _ - - - Malmquist Index Model 4

Fig. 5 Malmquist productivity indices for Models 1-4

\section{References}

Abbott M, Doucouliagos C (2009) Competition and efficiency: overseas students and technical efficiency in Australian and New Zealand universities. Educ Econ 17(1):31-57

Agasisti T, Bolli T (2013) The impact of the Bologna reform on the productivity of Swiss universities. High Educ Q 67:374-397

Agasisti T, Johnes G (2010) Heterogeneity and the evaluation of efficiency: the case of Italian universities. Appl Econ 42:1365-1375

Agasisti T, Pérez-Esparrells C (2009) Comparing efficiency in a cross-country perspective: the case of Italian and Spanish state universities. High Educ 17:31-57

Aghion P, Dewatripont M, Hoxby CM, Mas-Colell A, Sapir A (2008) Higher aspirations: an agenda for reforming European universities. Bruegel Blueprints 5
Atkinson S, Cornwell C, Honerkamp O (2003) Measuring and decomposing productivity change. J Bus Econ Stat 21: 284-294

Battese GE, Coelli TJ (1995) A model for technical inefficiency effects in a stochastic frontier production function for panel data. Empir Econ 20(2):325-332

Borghans L, Cörvers F (2009) The Americanization of Europes higher education and research. NBER working paper 15217

Caves DW, Christensen LR, Diewert WE (1982a) The economic theory of index numbers and the measurement of input, output, and productivity. Econometrica 50(6):1393-1414

Caves DW, Christensen LR, Diewert WE (1982b) Multilateral comparisons of output, input, and productivity using superlative index numbers. Econ J 92(365):73-86

Coelli T, Perelman S (2000) Technical efficiency of European railways: a distance function approach. Appl Econ 32(15):1967-1976

Coelli T, Rao D, O'Donnell C, Battese C (2005) An introduction to efficiency and productivity analysis, 2nd edn. Springer, Berlin

Confederation (1995) UAS law (Bundesgesetz über die Fachhochschulen)

Cornwell C, Schmidt P, Sickles R (1990) Production frontiers with cross-sectional and time-series variation in efficiency levels. J Econ 46:185-200

Crosier D, Purser L, Smidt H (2007) Trends v: Universities shaping the European higher education area. European University Association: Brussels

CRUS (2003) Richtlinien der SUK für die koordinierte Erneuerung der Lehre an den universitären Hochschulen der Schweiz im Rahmen des Bologna-Prozesses

Das A, Kumbhakar S (2012) Productivity and efficiency dynamics in Indian banking: an input distance function approach incorporating quality of inputs and outputs. J Appl Econ 27(2):205-234

Eckles J (2010) Evaluating the efficiency of top liberal arts colleges. Res High Educ 51:266-293

ETH (2004) Intellectual property right rules for the ETH domain (Bundesgesetz über die Eidgenössischen Technischen Hochschulen) 
Färe R, Grifell-Tatjé E, Grosskopf S, Know Lovell C (1997) Biased technical change and the Malmquist productivity index. Scand J Econ 99(1):119-127

Färe R, Grosskopf S, Lindgren B, Roos P (1994) Data envelopment analysis: theory, methodology, and applications. Kluwer Academic, Boston, Ch. productivity developments in Swedish hospitals: a Malmquist output index approach

Farsi M (2008) The temporal variation of cost efficiency in Switzerland's hospitals: an application of mixed models. J Product Anal 30:155-168

Filippini M, Lepori B (2007) Cost structure, economies of capacity utilization and scope in Swiss higher education institutions. In: Bonaccorsi A, Daraia C (eds) Universities and strategic knowledge creation. Edward Elgar, Specialisation and Performance in Europe

Flegg T, Allen D (2007) Does expansion cause congestion? The case of the older British universities, 1994-2004. Educ Econ 15:75-102

Flegg T, Allen D, Field K, Thurlow T (2004) Measuring the efficiency of British universities: a multi-period data envelopment analysis. Educ Econ 12:231-249

Fuentes HJ, Grifell-Tatjé E, Perelman S (2001) A parametric distance function approach for Malmquist productivity index estimation. J Product Anal 15:79-94

Garcia-Aracil A, Palomares-Montero D (2010) Examining benchmark indicator systems for the evaluation of higher education institutions. High Educ 60:217-234

Greene W (2005) Fixed and random effects in stochastic frontier models. J Product Anal 23:7-32

Horne J, Hu B (2008) Estimation of cost efficiency in Australian universities. Math Comput Simul 78:266-275

Johnes G, Johnes G (2008) Higher education institutions' costs and efficiency: taking the decomposition a further step. Econ Educ Rev 28:107-113

Johnes J (2004) The international handbook on the economics of education. Efficiency measurement. Edward Elgar, London

Johnes J (2008) Efficiency and productivity change in the English higher education sector from 1996/97 to 2004/5. Manch Sch 76:653-674

Kempkes G, Pohl C (2010) The efficiency of German universitiessome evidence from non-parametric and parametric methods. Appl Econ 42:2063-2079

Kneip A, Sickles R, Song W (2003) On estimating a mixed effects model with applications to the US banking industry. Rice University, Mimeo

Kruecken G (2007) Organizational fields and competitive groups in higher education: some lessons from the bachelor/master reform in Germany. Int Rev Manag Stud 18:187-203

Kuo H, Ho Y (2007) The cost efficiency impact of the university operation fund on public universities in Taiwan. Econ Educ Rev 27:603-612

Lee Y, Schmidt P (1993) The measurement of productive efficiency: techniques and applications. Oxford University Press, Oxford. $\mathrm{Ch}, \mathrm{A}$ production frontier model; with flexible temporal variation in technical efficiency

Malmquist S (1953) Index numbers and indifference surfaces. Trabajos de Estadística y de Investigación Operativa 4:209-242

Michaud P-A (2012) Reforms of the pre-graduate curriculum for medical students: the Bologna process and beyond. Swiss Med Wkly $142: 1-5$
Neave G, Amaral A (2008) On process, progress, success and methodology of the Bologna process as it appears to two reasonably benign observers. High Educ Q 62:40-62

Nishimizu M, Page JM (1982) Total factor productivity growth, technological progress and technological efficiency change: dimensions of productivity change in Yugoslavia, 1965-87. Econ J 92:920-936

Olivares M, Schenker-Wicki A (2012) The dynamics of productivity in the Swiss and German university sector: a non-parametric analysis that accounts for heterogenous production. UZH Business Working Paper Series 309

Olivares M, Wetzel H (2011) Competing in the higher education market: empirical evidence for economies of scale and scope in German higher education institutions. Leading House Working Paper Series 70

Orea L (2002) Parametric decomposition of a generalized Malmquist productivity index. J Product Anal 18:5-22

Patricio M, deBurbure C, Costa M, Schirlo C, Ten Cate O (2012) Bologna in medicine anno 2012: experiences of European medical schools that implemented a Bologna two-cycle curriculum. Med Teach 34:821-832

Robst J (2001) Cost efficiency in public higher education institutions. J High Educ 72:730-750

Saal D, Parker D, Weyman-Jones T (2007) Determining the contribution of technical change, efficiency change and scale change to productivity growth in the privatized English and Welsh water and sewerage industry: 1985-2000. J Product Anal 28:127-139

Swiss Federal Statistical Office (SFSO) (2010a) Classification of scientific fields (SHIS-Fächerkatalog universitäre Hochschulen). Available at http://www.bfs.admin.ch/bfs/portal/de/index/ infothek/nomenklaturen/blank/blank/faecherkatalog_hs/01.html. Accessed 29 May 2015

Swiss Federal Statistical Office (SFSO) (2010b) Indicators of the swiss higher education sector (Hochschulen-Indikatoren, Tertiärstufe). Available at http://www.bfs.admin.ch/bfs/portal/de/ index/themen/15/06/data/blank/01.html. Accessed 29 May 2015

Sickles R (2005) Panel estimators and the identification of firmspecific efficiency levels in parametric, semiparametric and nonparametric settings. J Econom 126:305-334

Stevens P (2005) A stochastic frontier analysis of English and Welsh universities. Educ Econ 13:355-374

SUC (2003) Quality assurance guidelines (Richtlinien der Schweizerischen Universitätskonferenz für die Akkreditierung im universitären Hochschulbereich)

Thanassoulis E, Kortelainen M, Johnes G, Johnes J (2009) Costs and efficiency of higher education institutions in England: a dea analysis. Lancaster University Management School Working Paper 8

Veiga A, Amaral A (2009) Survey on the implementation of the Bologna process in Portugal. High Educ Econ 57:57-69

Witte J (2008) Aspired convergence, cherished diversity: dealing with the contradictions of Bologna. Tert Educ Manag 14:81-93

Worthington A, Lee B (2008) Efficiency, technology and productivity change in Australian universities, 1998-2003. Econ Educ Rev 27:285-298

Worthington AC (2001) An empirical survey of frontier effciency measurement techniques in education. Educ Econ 9:245-268 